\title{
Prevalence of Anemia Risk Factors in Pregnant Women
}

\author{
Dr. Seema Kumari ${ }^{1}$, Dr. Jyoti Priya ${ }^{2}$ \\ ${ }^{1}$ Assistant Professor Department of Physiology, Hind Institute of Medical Sciences , Mau, Ataria, Sitapur \\ ${ }^{2}$ Assistant Professor Department of Physiology, VIMS, Pawapuri, Nalanda Bihar
}

\begin{abstract}
Objective: To study the prevalence and risk factors of women with anemia during pregnancy. Materials and methods: This study was performed based on 100 pregnancies delivered during the years 2016 in Hind institute of medical sciences. Anemia was defined as hemoglobin $(\mathrm{Hg})$ lower than $11 \mathrm{~g} / \mathrm{dl}$ during pregnancy. This test were estimated by hemoglobinometer. Result: Out of 100 pregnant women, 40 (40\%) pregnant women were anemic and 60 pregnant women were non anemic (60\%). Also, among these anemic pregnant women, majority (55 \%) of these women were mildly anemic, whereas $35 \%$ were moderately and $10 \%$ were severely anemic. Conclusion: Prevalence of anemia was higher in the pregnant women at the second trimester (51.1\%) and also at the 20-35 years age group (62.79\%).
\end{abstract}

Keywords: Pregnancy, Anemia, Prevalence, Hb concentration

\section{Introduction}

World Health Organization defines anemia as hemoglobin below $11 \mathrm{~g} / \mathrm{dl}$ as the lower limit acceptable and $10.5 \mathrm{~g} / \mathrm{dl}$ in the second half of pregnancy. Anemia can further be classified into mild anemia (10 -10.9g/dl), moderate anemia $(7-9.9 \mathrm{~g} / \mathrm{dl})$ and severe anemia $(<7 \mathrm{~g} / \mathrm{dl})[1]$.

The prevalence of anemia in pregnancy varies considerably because of differences in socioeconomic conditions, lifestyles and health seeking behaviors across different cultures.[2]

Pregnancy is a period of a significant increase in iron requirement over and above the non-pregnant state[3]. Although iron requirements are reduced in the first trimester because of the absence of menstruation, they rise steadily thereafter from approximately $0.8 \mathrm{mg}$ per day in the first month to approximately $10 \mathrm{mg}$ per day during the last 6 weeks of pregnancy[4]. The increased iron requirement is due to expansion of maternal red blood cell mass for increased oxygen transport, including transfer of iron, to both the growing foetus and the placental structures, and as a needed reserve for blood loss and lochia at parturition[5]. Due to increased iron requirements, pregnancy is also a period of increased risk for anaemia. Thus, a high proportion of women become anaemic during pregnancy.

Women go through a variety of physiological changes during pregnancy. Changes in the blood circulatory system are particularly notable, permitting normal fetal growth. Even in normal pregnant women, the hemoglobin concentration decreases with dilution according to the increase in the volume of circulating blood. Since iron and folic acid in amounts necessary to the fetus are preferentially transported to the fetus, the mother is likely to develop iron deficiency anemia and folic acid deficiency anemia. About $20 \%$ of pregnant women suffer anemia, and most of the cases are iron deficiency, folic acid deficiency, or both [6]

\section{Materials and Methods}

\section{Study area and Duration}

The study was conducted on hemoglobin that obtained from blood sample of anemic pregnant women submitted to laboratory from February 2016 to march 2016 at Hind institute of medical sciences.

\section{Study Population}

Blood sample were collected from a total of 100 anemic pregnant women. All these pregnant women in-patients attending the hind institute of medical sciences.

We included only those who came to Hind Hospital for antenatal check up and came for delivery as well. As anemia is classified into three degree according to WHO are mild, moderate and severe. $\mathrm{Hb}$ cut-off values of anemia were $10.0-11.9 \mathrm{~g} / \mathrm{dl}$ (mild), 7.0-9.9 g/dl (moderate) and $<7.0 \mathrm{~g} / \mathrm{dl}$ (severe).7 World Health Organization's guideline was used for interpretation and classification of anemia.[7]

\section{Results}

A total of 100 pregnant women samples were collected and analyzed for this study from February 2016 to March 2016. The age group for this study was considered from 18-45 years.

Table 1 shows that among the total pregnant women, 40 (40\%) pregnant women were anemic and 60 pregnant women were non anemic $(60 \%)$.

Table 1: Anemic and Non anemic pregnant women

\begin{tabular}{|c|c|c|}
\hline Total pregnant women & Anemic & Non anemic \\
\hline 100 & $40(40 \%)$ & $60(60 \%)$ \\
\hline
\end{tabular}

Also, among these anemic pregnant women, majority (67.14\%) of them were mildly anemic, whereas $28.57 \%$ were moderately and $4.29 \%$ were severely anemic as can be seen in Table 2. 


\section{International Journal of Science and Research (IJSR) \\ ISSN (Online): 2319-7064 \\ Index Copernicus Value (2013): 6.14 | Impact Factor (2015): 6.391}

Table 2: Grading of anemia

\begin{tabular}{|c|c|c|c|c|}
\hline Age Group & Mild & Moderate & Severe & Prevalence \\
\hline $18-20$ & 5 & 3 & 2 & $10(25 \%)$ \\
\hline $21-35$ & 12 & 8 & 1 & $21(52.5 \%)$ \\
\hline$>36$ & 5 & 3 & 1 & $9(22.5 \%)$ \\
\hline Total & $22(55 \%)$ & $14(35 \%)$ & $4(10 \%)$ & $40(100 \%)$ \\
\hline
\end{tabular}

\section{Discussion}

During this study, out of 100 pregnant women, 40 (40\%) pregnant women were anemic and 60 pregnant women were non anemic (60\%). Also, among these anemic pregnant women, majority (55\%) of these women were mildly anemic, whereas $35 \%$ were moderately and $10 \%$ were severely anemic.

Our study further revealed that anemia was mostly recorded at the age group of 20-35 years and those at the second trimester of pregnancy. Results of our work corroborates well with the reports of WHO on the prevalence of anemia in developing countries.1 Data of our study indicates that the prevalence of anemia in our study was closer to that recorded among the pregnant women of Biratnagar, Nepal (47.25\%) and Venezuela (34.4\%) which further supports our interpretation.[8,9]

Our observation is quite in agreement with the earlier observation that iron deficiency is the commonest cause of anemia in developing countries and that is why WHO has emphasized on the need of epidemiological studies.[10,11]

Ma AG and Chen XC et al (2004) reported 41.58\% in pregnant people of Qingdao province of China were anemic and the subjects with iron deficiency anemia had much higher rates of vitamin $\mathrm{C}$, folate and B12 deficiencies than those in the non anemic subjects and especially in the deficient rates of ascorbic acid and folate in the anemia group. Moreover, they observed that the decreasing trends of $\mathrm{Hb}$ concentrations were accompanied by the decreases of serum levels of vitamin A, ascorbic acid, folate and B12 and concluded that multiple vitamin deficiencies may be associated with anemia in pregnant mothers in the last trimester.[12] However, the work of Karaoglu et al (2010) on pregnant women of East Anatolian province of Turkey, registered a percentage of $27.1 \%$ of anemic pregnant women.[13]

\section{Conclusion}

Prevalence of anemia was higher in the pregnant women at the second trimester (51.1\%) and also at the 20-35 years age group (62.79\%).

\section{References}

[1] World Health Organization (WHO). The prevalence of Anemia in women: A tabulation of available information. Geneva, Switzerland: WHO; 1992. WHO/MCH/MSM/92.2

[2] Marchant T, Armstrong S and Edgar T et al. Anemia during pregnancy in Southern Tanzania. Annals Trop Ted Parasit 2002; 96: 477-8. 3. Abou Zahr C and
Royston E. Maternal mortality. A global fact book. WHO, Geneva, 1991.

[3] Zavaleta N, Caulfield L, Garcia T. Changes in iron status during pregnancy in Peruvian women receiving prenatal iron and folic acid supplements with or without zinc. Journal of American Nutrition 2000; 71: 956-961.

[4] Bothwell $\mathrm{T} \mathrm{H}$. Iron requirements in pregnancy and strategies to meet them. American Journal of Clinical Nutrition 2000; 72(1): 257S-S264.

[5] Beaton GH. Iron needs during pregnancy: do we need to rethink our targets? American Journal of Clinical Nutrition 2000; 72(1): 265S-271S.

[6] Shiro KOZUMA, 'Approaches to Anemia in Pregnancy', JMAJ 52(4) Page no 214-218, 2009.

[7] WHO Groups of Experts on Nutritional Anemia. Technical Report Series. WHO, Geneva 1986.

[8] A.K.Sinha , Gyanendra Mansingh Karki, Sanjay Yadav, and Md. Nazrul Islam. Prevalence of Anemia during Pregnancy in the Women of Eastern Nepal. International Journal of Pharmaceutical \& Biological Archives 2012; 3(5):1051-1053.

[9] Marti-Carvajal et al; Prevalence of anemia during pregnancy: Results of Valencia- Venezuela. Arch Latino Amer De Nutricion 2002; 1: 52. 11.

[10]Lone FW, Qureshi RN and Emmanuel F. Maternal anemia and its perinatal outcome in a tertiary care hospital in Pakistan. Eastern Mediterranean Health J 2004; 10: 801 - 7.

[11]WHO. Mother Baby package: Implementation Safe Motherhood in Developing Countries. Geneva, 1994.

[12] Ma AG \& Chen XC et al (2004); The multiple vitamin status of Chinese pregnant women with anemia and non anemia in the last trimester. J Nutr Sci Vitaminol Tokyo, Apr. 2004, 50(2):87-92.

[13] Karaoglu et al ;The prevalence of nutritional anaemia in pregnancy in an East Anatolian province ,Turkey. BMC public Health 2010,10:329. 